\title{
Article \\ Estimation of Stock Status Using the LBB and CMSY Methods for the Indian Salmon Leptomelanosoma indicum (Shaw, 1804) in the Bay of Bengal, Bangladesh
}

\author{
Md. Abdullah Al-Mamun ${ }^{1,2} \mathbb{D}$, Md. Mostafa Shamsuzzaman ${ }^{3} \mathbb{D}$, Petra Schneider ${ }^{\mathbb{D}}$, Mohammad Mojibul \\ Hoque Mozumder ${ }^{5}$ and Qun Liu ${ }^{1, *}$
}

\section{check for}

updates

Citation: Al-Mamun, M.A.

Shamsuzzaman, M.M.; Schneider, P.; Mozumder, M.M.H.; Liu, Q. Estimation of Stock Status Using the LBB and CMSY Methods for the Indian Salmon Leptomelanosoma indicum (Shaw, 1804) in the Bay of Bengal, Bangladesh. J. Mar. Sci. Eng. 2022, 10, 366. https://doi.org/ 10.3390/jmse10030366

Academic Editor: Dariusz Kucharczyk

Received: 29 January 2022

Accepted: 23 February 2022

Published: 4 March 2022

Publisher's Note: MDPI stays neutral with regard to jurisdictional claims in published maps and institutional affiliations.

Copyright: (C) 2022 by the authors. Licensee MDPI, Basel, Switzerland. This article is an open access article distributed under the terms and conditions of the Creative Commons Attribution (CC BY) license (https:// creativecommons.org/licenses/by/ $4.0 /)$.
1 College of Fisheries, Ocean University of China, Qingdao 266003, China; mamunbau09@yahoo.com

2 Department of Fisheries, Ministry of Fisheries \& Livestock, Dhaka 1217, Bangladesh

3 Department of Coastal and Marine Fisheries, Sylhet Agricultural University, Sylhet 3100, Bangladesh; shamsuzzamanmm.cmf@sau.ac.bd

4 Department for Water, Environment, Civil Engineering and Safety, University of Applied Sciences Magdeburg-Stendal, Breitscheidstraße 2, D-39114 Magdeburg, Germany; petra.schneider@h2.de

5 Fisheries and Environmental Management Group, Helsinki Institute of Sustainability Science (HELSUS), Faculty of Biological \& Environmental Sciences, University of Helsinki, 00014 Helsinki, Finland; mohammad.mozumder@helsinki.fi

* Correspondence: qunliu@ouc.edu.cn; Tel.: +86-136-8542-6216

\begin{abstract}
As one of the largest and most commercially valuable finfish species, Leptomelanosoma indicum (Indian salmon) significantly contributes to Bangladesh's marine catches. The length-based Bayesian biomass (LBB) method and catch-based Monte Carlo method (CMSY) are among the most recent and powerful methods for predicting the state of fisheries resources from data-limited fisheries. CMSY requires catch and resilience data, as well as quantitative stock status information. For LBB, only length-frequency $(L F)$ data are required. The stock status of $L$. indicum was estimated using these two independent methods, utilizing twenty-one years of catch-effort and length-frequency data (978 individuals) from commercial fisheries on the Bangladesh coast. Here, a BSM (Bayesian statespace implementation of the Schaefer surplus production model) was also employed. The current study's findings showed that the $B / B_{0}$ ratio of currently exploited biomass to unexploited biomass (0.1) was smaller than $B_{M S Y} / B_{0}(0.36)$ and $B / B_{M S Y}=0.28$ was smaller than the reference value of 1.0, indicating the grossly overfished and depleted condition of the stock. Similar trends in the results were found for $B / B_{M S Y}=0.11(<1.0)$ from CMSY. In addition, the exploitation rate $\left(F / F_{M S Y}=5.66\right)$, biomass $\left(B<B_{M S Y}\right)$, and fishing status $\left(F>F_{M S Y}\right)$ further justify the severely overfished conditions of L. indicum stock in the study area. Furthermore, the $L_{c_{-} \text {opt }}$ (optimal length at first capture) was higher than the $L_{c}$ (length at first capture), indicating that this species is being overfished, and that mesh sizes should be increased for better management. This study provides information on biological reference points (BRPs), and confirms the severely overfished status of L. indicum in the coastal waters of Bangladesh. More specific and prompt management measures are required to recover and sustainably manage this valuable species, and protect the fish stock from commercial extinction.
\end{abstract}

Keywords: LBB; CMSY; Leptomelanosoma indicum; BRPs; Bay of Bengal

\section{Introduction}

The outputs of stock assessment studies provide significant information for successful policy making for fisheries resources, which is crucial for the sustainable management of fisheries. Scientists assess the status of fisheries stocks to offer biological reference points (BRPs), calculated using various statistical approaches [1-5]. Both scientists and managers must consider this information about the stock status and its response to the existing degree of removal to investigate the future possibilities for sustainable exploitation of the fishery [6-8]. The coastal and marine environment of Bangladesh is characterized by a 
warm tropical climate and substantial rainfall, which is loaded with various nutrients from the land, resulting in one of the world's richest and most productive ecosystems $[9,10]$. These diverse coastal and marine environments support over 511 marine species, including fish, shrimp, mollusks, mammals, crabs, seaweeds, etc. [11].

Leptomelanosoma indicum (Shaw, 1804) belongs to the family Polynemidae, and is often referred to as Indian salmon or Indian threadfin, and locally called "lakkha". It is also referred to as Polydactylus or Polynemus indicus in previous literature and reports [12]. As a commercially valuable single fishery, Indian salmon has made a significant contribution to the country's marine fisheries catches over the last decade; however, indiscriminate overfishing has negatively influenced the recent catches of this stock [13]. This is generally distributed in the Indo-West Pacific region, currently recognized from South Africa [14], Sri Lanka, and Western India [15], as well as Northern Australia, Singapore, Malaysia, Thailand, Myanmar, Bangladesh and Eastern India [16].

The resources in the Bay of Bengal (BoB) have generally been over-exploited, resulting in a reduction in fish stocks. The larger-bodied and generally more important species groups, including L. indicum (Indian Salmon), display more signs of depletion and overfishing, with some exceptional catches that were usually incidental, i.e., not explicitly targeted by fishers, indicating that they are in need of rebuilding [17,18]. Trawl nets and large mesh drift gillnets (LMDs) are usually used to catch Indian salmon in the BoB, on the coast of Bangladesh. As a target species of LMDs, L. indicum is now almost extinct in Bangladeshi seas [19].

Considering the commercial value of this significant fishery inside and outside the country, there is no comprehensive study on the stock status of this valuable species in this area. However, the declining stock status of this species has been mentioned in many technical reports and articles based on historical data of the catch-effort method from the commercial landing $[13,18,19]$. Due to a lack of data and required expertise in Bangladesh, only a tiny portion of commercially harvested stocks has been studied until today. This is similar to many other places around the world, where fishery research has languished. Recently data-limited methods were developed in response to the current situation. Using catch statistics and supplementary data, CMSY method attempted to determine the maximum sustainable yield (MSY) and related biological population parameters $[2,20]$. The alternative method of LBB relies on $L F$ (length-frequency) data to arrive at conclusions about population growth $(G)$, mortality $(M)$, and, consequently, responses to exploitation [21-23].

In this study, we have applied the most recent and powerful methods of length-based Bayesian biomass (LBB) and catch-based Monte Carlo (CMSY) for estimating the existing status of L. indicum stock in the BoB, on the coast of Bangladesh, and to give advice for the protection and long-term management of this commercially valuable fishery resource in this region.

\section{Materials and Methods}

\subsection{Data Sources}

CMSY and LBB analyses were conducted using a time series of maritime catch-effort and length-frequency data from the Indian salmon fishery in the BoB, Bangladesh coast (Figure 1). Capture data from industrial and artisanal fisheries were collected for 21 years (1999-2019) from the Fisheries Statistical Year Book of Bangladesh, published by the Department of Fisheries (DoF), Bangladesh. In addition, the length-frequency ( $L F)$ data of 978 samples of L. indicum were collected directly from the commercial fishing fleets on board the vessels during the landing period. For each fish sampled, length and weight data were measured by metric scale to the nearest $\mathrm{mm}$ and g, respectively, on board the vessel, with the cooperation of fishers, vessel owners and concerned marine fishery officials of the Department of Fisheries. Total capture data were valued in tons $(t)$, and catch per unit of effort (CPUE) was calculated in tons per gear per year $(\mathrm{t} / \mathrm{g} / \mathrm{yr})$ for the catch and effort data utilized for CMSY analysis. 


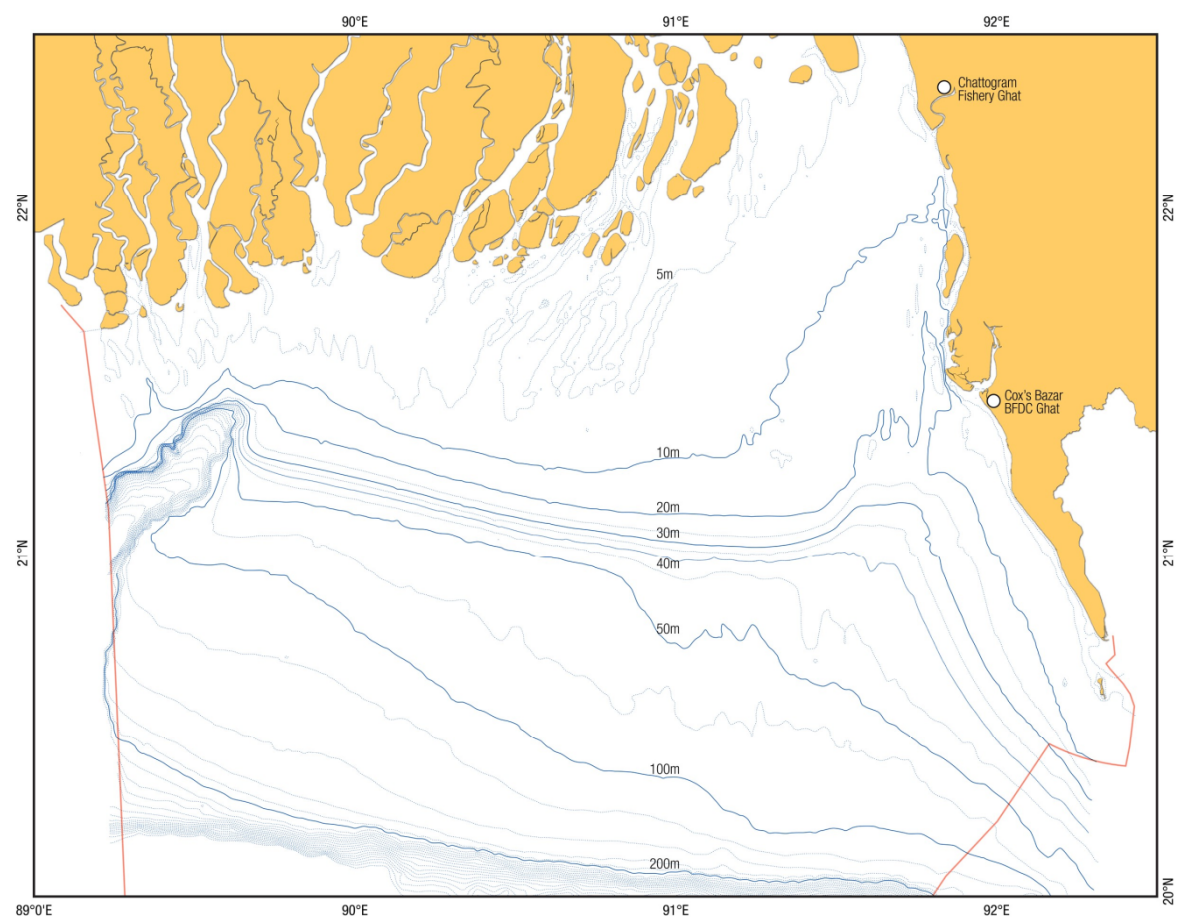

Figure 1. Bay of Bengal, Bangladesh coastal map showing the different depth zones within the fishing grounds.

The $L F$ and catch-effort data were analyzed in the $\mathrm{R}$ statistical environment using the R codes LBB 33a.R and CMSY 2019 9f.R, which were produced by Froese et al., 2019a, 2019b [24,25], and were downloaded from http://oceanrep.geomar.de/44832/ (accessed on 20 September 2021) and https:/ / oceanrep.geomar.de/33076/ (accessed on 12 November 2021), respectively. During CMSY, JAGS software [26] was used to sample parameter probability distributions using a Markov Chain Monte Carlo approach.

\subsection{Description of the LBB Method}

Froese et al., 2018 [27], developed LBB, a new approach for analyzing LF data from the exploited fisheries. LBB requires no input other than length-frequency data for species that grow throughout their lifetimes, such as most economically significant fish and invertebrates. It calculates the $L_{\text {inf }}, L_{\mathcal{C}}, M$ (natural mortality), and $F$ (fishing mortality) relative to each other [24,27]. Using these data as the input, standard fisheries equations can be applied to assess depletion or current exploited biomass comparative to unexploited biomass $\left(B / B_{0}\right)$. These factors also allow for an estimate of a proxy for the relative biomass capable of delivering the $B_{M S Y} / B_{0}$ and $L_{c}$ that would optimize catch and biomass for a given $L_{c o p t}$. The relative biomass predicted by LBB was comparable to independent estimates from comprehensive stock assessments and did not statistically deviate from "actual" values in simulated data [27]. The comprehensive information with a detailed description of the LBB method can be found in [24,27]. $L F$ data for the commercially valuable $L$. indicum species (Table 1) from the BoB, on the coast of Bangladesh, were investigated in this study.

Table 1. Basic and prior information for LBB approach.

\begin{tabular}{|c|c|c|c|c|c|c|c|c|c|c|c|}
\hline $\begin{array}{l}\text { Scientist } \\
\text { Name }\end{array}$ & $\begin{array}{l}\text { Common } \\
\text { Name }\end{array}$ & $\begin{array}{l}\text { Min } \\
(\mathrm{cm})\end{array}$ & $\begin{array}{l}\text { Max } \\
\text { (cm) }\end{array}$ & $\begin{array}{l}\text { Class } \\
\text { Interval }\end{array}$ & Numbers & $\begin{array}{l}L_{\text {inf }} \\
\text { Prior } \\
\text { (cm) }\end{array}$ & $\begin{array}{l}Z / K \\
\text { Prior }\end{array}$ & $\begin{array}{l}M / K \\
\text { Prior }\end{array}$ & $\begin{array}{c}F / K \\
\text { Prior }\end{array}$ & $L_{c}$ Prior & $\begin{array}{c}\text { Alpha } \\
\text { Prior }\end{array}$ \\
\hline $\begin{array}{l}\text { Leptomelanosoma } \\
\text { indicum }\end{array}$ & $\begin{array}{l}\text { Indian } \\
\text { Salmon }\end{array}$ & 24 & 91 & 1 & 978 & 109 & 3.4 & 1.5 & 1.89 & 33.7 & 26.4 \\
\hline
\end{tabular}




\subsection{Description of CMSY and BSM}

The CMSY and BSM approaches were used to estimate the $M S Y, B / B_{M S Y}$, exploitation $\left(F / F_{M S Y}\right)$, and other relevant BRPs using time series of catch, CPUE, and resilience data. Different parameters, such as the maximum intrinsic growth rate of population $(r)=r_{\max }$ and carrying capacity $(k)$, are projected from [28].

$$
B_{t+1}=B_{t}+r\left(1-\frac{B_{t}}{k}\right) B_{t}-C_{t}
$$

where $B_{t+1}$ is the exploited biomass in the following $(t+1)$ year, $B_{t}$ is the current biomass, and $C_{t}$ is the catch in year $t$. The following equation was used to clarify the reduced recruitment at harshly depleted stock sizes, where biomass falls below $\frac{1}{4} k$ :

$$
B_{t+1}=B_{t}+4 \frac{B_{t}}{k} r\left(1-\frac{B_{t}}{k}\right) B_{t}-C_{t} \mid \frac{B_{t}}{k}<0.25
$$

Resilience for Indian salmon is "medium" according to Fishbase [29], and for CMSY+, the prior range (Table 2) chosen for parameter $r$ was $0.2-0.8$. By default, depending on the presumed depletion level, the probable biomass ranges (Table 3) deliver prior estimations of relative biomass at the start and end of the time series data.

Table 2. Prior $r$ ranges used for CMSY+.

\begin{tabular}{ccccc}
\hline Resilience & High & Medium & Low & Very Low \\
\hline Prior $r$ range & $0.6-1.5$ & $0.2-0.8$ & $0.05-0.5$ & $0.015-0.1$ \\
\hline
\end{tabular}

Table 3. Prior relative biomass ranges (B/K) for CMSY+.

\begin{tabular}{ccccc}
\hline $\begin{array}{c}\text { Very Strong } \\
\text { Depletion }\end{array}$ & Strong Depletion & Medium Depletion & Low Depletion & $\begin{array}{c}\text { Nearly } \\
\text { Unexploited }\end{array}$ \\
\hline $0.01-0.2$ & $0.01-0.4$ & $0.2-0.6$ & $0.4-0.8$ & $0.75-1.0$ \\
\hline
\end{tabular}

In the following equation, the catchability coefficient $(q)$ relates the abundance index to the stock biomass:

$$
\text { CPUE } E_{t}=q B_{t}
$$

where $C P U E_{t}$ is the average CPUE in year $t, B_{t}$ is biomass in the year $t$, and $q$ is catchability coefficient for a data-limited fishery.

CMSY and BSM parameters were estimated $[20,30]$ as $M S Y=r k / 4$, biomass corresponding to $M S Y$ was $B_{M S Y}=0.5 k$, fishing mortality corresponding to $M S Y$ was $F_{M S Y}=0.5 r$, and biomass below which recruitment may be compromised 0.5 of the $B_{M S Y}$ [31-33]. Table 4 represents CMSY input values (biomass, $r, k$, and $q$ ranges) for prior distribution.

Table 4. Relative biomass, ranges for $r, k, q$ as priors in CMSY+ of L. indicum in BoB.

\begin{tabular}{ccccc}
\hline $\begin{array}{c}\text { Input } \\
\text { Parameters }\end{array}$ & $\begin{array}{c}\text { Prior Initial } \\
\text { Relative Biomass }\end{array}$ & $\begin{array}{c}\text { Prior Intermediate } \\
\text { Relative Biomass }\end{array}$ & $\begin{array}{c}\text { Prior Final } \\
\text { Relative Biomass }\end{array}$ & Prior Range for $\boldsymbol{r}$ Prior Range of $\boldsymbol{q}$ Prior Range for $\boldsymbol{k}$ \\
\hline $\begin{array}{c}\text { Ranges of the } \\
\text { values }\end{array}$ & $0.4-0.8$ & $\begin{array}{c}0.01-0.4 \\
\text { In year }(2015)\end{array}$ & $0.01-0.1$ & $\begin{array}{c}1.54 \times 10^{-06}- \\
6.16 \times 10^{-06}\end{array}$ \\
\hline
\end{tabular}




\section{Results}

\subsection{Parameters Produced by the LBB Approach}

The length-frequency data for Indian salmon (L. indicum) from the BoB, on the coast of Bangladesh, were analyzed using the LBB method. Table 1 shows the priors ( $\inf , L c, M / K$, $Z / K, F / K$, and $a$ ) and basic information for this fisheries stock, while Figure 2 shows the calculated results. Table 5 provides comprehensive information on the calculated parameters.

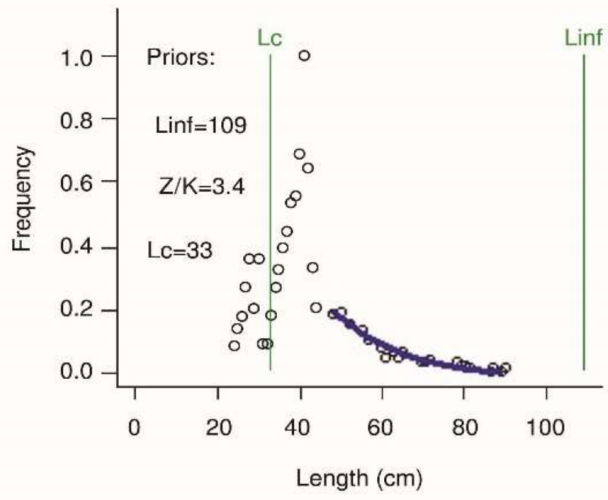

(A)

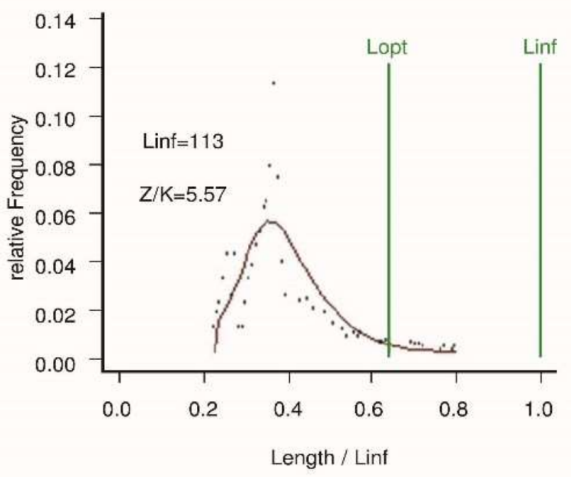

(B)

Figure 2. The graphical outputs of LBB for the Indian Salmon. Panel-(A) displays the accumulated length frequency $(L F)$ data analyzed for estimating the priors for $L_{c,}, Z / K$ and $L_{\text {inf }}$. Panel-(B) shows the $L_{\text {opt }}, L_{\text {inf }}$ and $Z / K$ assessed by the fitting curve.

Table 5. Estimated results from length-frequency data of L. indicum by the LBB method.

\begin{tabular}{cccccccccc}
\hline Scientist Name & $L_{\text {mean }} / L_{\text {opt }}$ & $L_{\mathcal{c}} / L_{\mathcal{C} \__{-} \text {opt }}$ & $L_{95 t h} / L_{\text {inf }}$ & $B / B_{0}$ & $B / B_{M S Y}$ & $F / M$ & $F / K$ & $Z / K$ & Assessment \\
\hline Leptomelanosoma indicum & 0.61 & 0.53 & 0.81 & 0.10 & 0.28 & 2.3 & 3.9 & 5.5 & $\begin{array}{c}\text { Grossly } \\
\text { overfished }\end{array}$ \\
\hline
\end{tabular}

The present study found that the ratio of current exploited biomass relative to unexploited biomass $B / B_{0}(0.10)$ was smaller than the $B_{M S Y} / B_{0}(0.36)$ and $B / B_{M S Y}=0.28$ was smaller than the reference value of 1.0 , which indicates the grossly overfished condition of the stock. The $L_{c_{-} \text {opt }}$ was higher than the $L_{c}$, which indicates growth overfishing of this species. The poor presence of large individuals is suggested from the $L_{95} / L_{i n f}=0.81$ value in this study area (Figure 2).

\subsection{Fisheries Reference Points (BRPs) Produced from CMSY and BSM}

The BSM-derived BRPs for the L. indicum fishery in the study area are shown in Table 6. The biomass $(1620 \mathrm{t})$ was significantly lower than the $B_{M S Y}(15,600 \mathrm{t})$ and the fishing mortality $\mathrm{F}$ was higher than $F_{M S Y}$, which denotes the severely exploited condition of this fishery in the $\mathrm{BoB}$, on the coast of Bangladesh (Figure 3). In addition, the findings of $B / B_{M S Y}=0.11(<1.0)$ and exploitation $\left(F / F_{M S Y}=5.66\right)$ further justify the severely exploited conditions of L. indicum stock in the study area (Figure 4).

Table 6. Estimated results with $95 \%$ confidence interval for management based on BSM analysis from catch and effort data using BSM method.

\begin{tabular}{ccccccccc}
\hline BRPs & $\boldsymbol{r}(\mathbf{y r})$ & $\boldsymbol{F}(/ \mathbf{y} r)$ & $\boldsymbol{F}_{\mathrm{MSY}}(/ \mathbf{y} \boldsymbol{r})$ & $\boldsymbol{B}(\boldsymbol{t})$ & $\boldsymbol{B}_{\mathrm{MSY}}(\boldsymbol{t})$ & $\boldsymbol{F} / \boldsymbol{F}_{\mathrm{MSY}}$ & $\boldsymbol{B} / \boldsymbol{B}_{\mathrm{MSY}}$ & $\boldsymbol{M S Y}(\boldsymbol{t})$ \\
\hline BSM & 0.32 & 0.17 & 0.03 & 1620 & 15,600 & 5.66 & 0.11 & $(1820-3410)$ \\
\hline
\end{tabular}



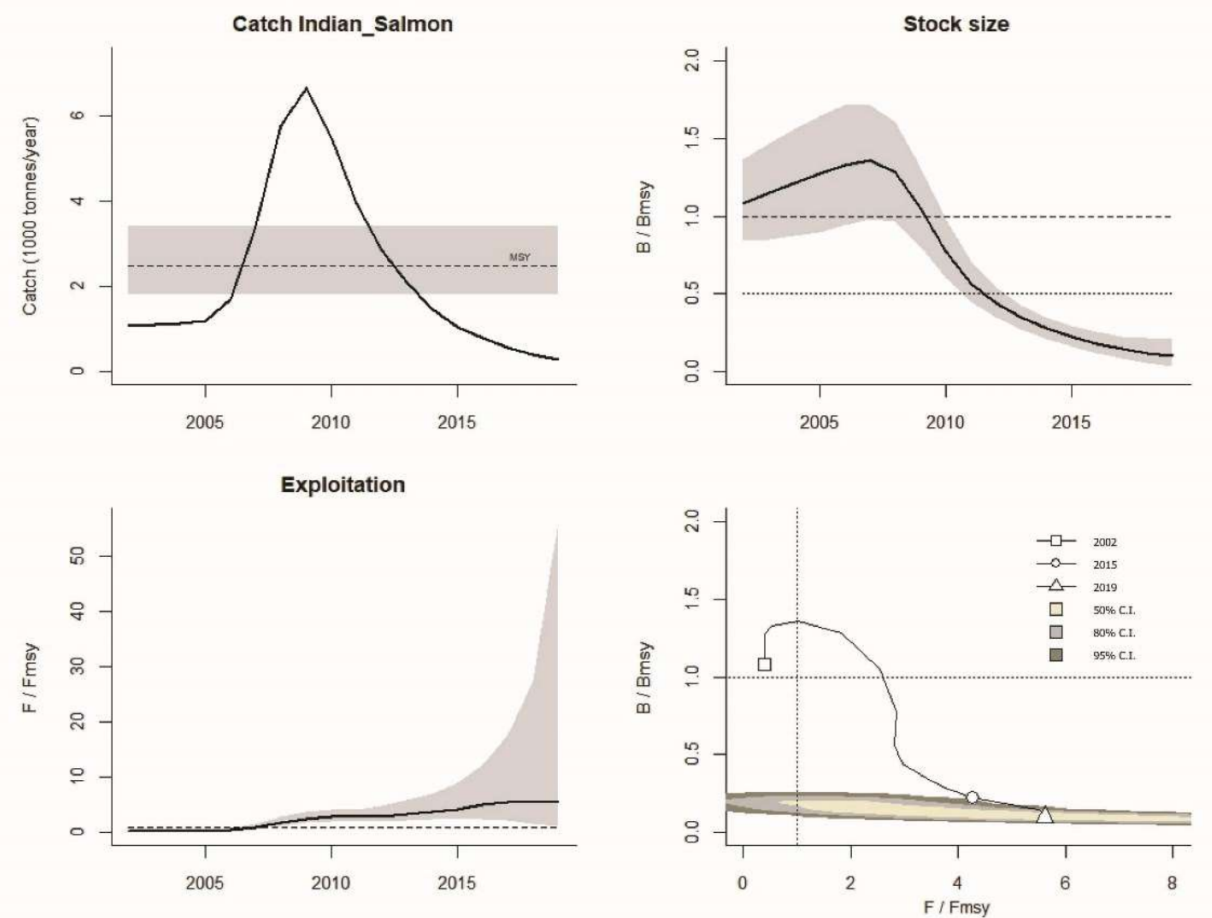

Figure 3. Graphical findings of BSM method for the L. indicum fishery in the BoB, Bangladesh coast.

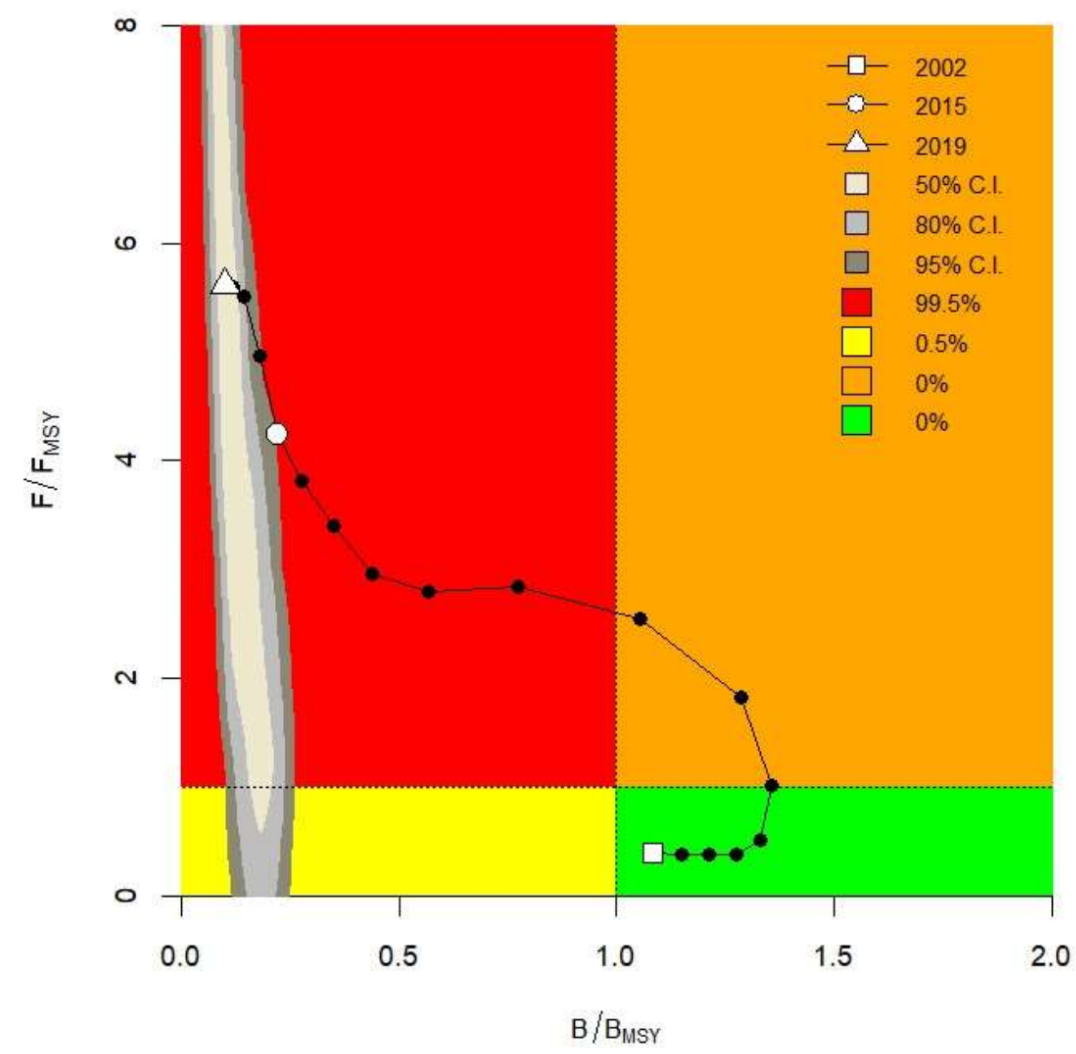

Figure 4. Kobe plot of BSM for the Indian salmon fishery in the BoB, Bangladesh coast. 


\section{Discussion}

CMSY [2] is a catch-based Monte Carlo approach that is best for calculating BRPs where fisheries data are limited. Only catch and resilience data are required for the CMSY model. CMSY has been reported to outperform other methods for estimating BRPs, and to be more practical for short time series data in developing and least-developed countries $[4,8,34,35]$. BSM can be used if CPUE data are available [2]. The LBB approach uses Bayesian Markov Chain Monte Carlo (MCMC) to analyze $L F$ data from commercial fish or invertebrate populations [27]. Thus, even in data-poor situations, fishery managers may rely on LBB assessments for stock estimation procedures which can produce a reasonable assessment of biomass relative to unfished biomass. Here, we have considered 21 years of catch-effort data and two years of LF data, using two different powerful models, CMSY and LBB, respectively, with the 'medium resilience' value (Table 2) collected from the updated life history parameters in Fishbase [29].

The proxies for the $B / B_{0}(0.4-0.5)$ [27] and $B / B_{M S Y}(1)[27,36]$ can be considered as the lower boundaries of expected stock sizes. The values of $B / B_{M S Y}$, produced by both the LBB and CMSY approaches, are $<1.0(\mathrm{LBB}=0.28$ and CMSY $=0.11)$, which indicates the severely overfished and depleted condition of the Indian Salmon stock in the current study area. In addition, the biomass from the last year $(1620 \mathrm{t})$ was much lower than the $B_{M S Y}$ $(15,600 \mathrm{t})$, and the current fishing status $\left(F>F_{M S Y}\right)$ indicates the severely depleted and overfished status of this fishery in the BoB, on the coast of Bangladesh. It may be assumed that this continuous overexploitation for a long period would severely deplete the stock, resulting in the poor condition of the existing biomass of L. indicum in the BoB, on the coast of Bangladesh.

There is not sufficient published information on BRPs that compares different parameters of this species in the present study area. However, in previous studies, many authors reported the severely overfished status of the L. indicum fishery in the BoB, on the coast of Bangladesh $[13,18,19]$, which agrees with the present study. For the past two decades, large mesh drift gillnets (LMDs) have been used in the BoB, on the coast of Bangladesh, to catch L. indicum (Indian salmon) and long jewfish. These species have been overfished to the point of extinction [9], which also coincides with our findings of a high exploitation status $\left(F / F_{M S Y}=5.66\right), B / B_{M S Y}=0.11$, as calculated by $B S M$, and $B / B_{M S Y}=0.28$, as determined by LBB, in the present study. In addition, [37] reported the collapsed stock status of threadfins (Polynemus spp.) in 2013 in the northern Bay of the Bengal area, which also strongly supports the severely overfished and depleted conditions of L. indicum estimated by the present study.

Furthermore, the results of the LBB analysis showed that the $L_{c_{-} \text {opt }}$ (optimal length at first capture) was higher than the $L_{\mathcal{C}}$ (length at first capture), indicating that the Indian salmon is being overfished, and implying that mesh sizes should be increased for better management. Overfishing may disrupt the delicate balance of fish species and other marine organisms in the ocean, and overfishing for a specific species may result in its depletion. Continual overfishing may alter the food chain and truncate the food web, posing a threat to the health of the ocean, with ramifications for all living things $[5,38,39]$. The findings of this study confirm that $L$. indicum has been severely overfished for a long period in the coastal waters of Bangladesh. More targeted and quick management approaches are required to rehabilitate and manage this valuable species sustainably.

\section{Conclusions}

The current study applied two recent and powerful methods for estimating the stock status of Indian salmon (Leptomelanosoma indicum). Both methods exhibited similar results, identifying the severely overfished and depleted condition of this stock, which is very alarming for this commercially valuable and giant-sized Indian threadfin, L. indicum, fishery. These findings will help to formulate management strategies and conservation policies for protecting this valuable fish stock from extinction, and assist further development of this fishery in the $\mathrm{BoB}$, on the coast of Bangladesh. 
Author Contributions: M.A.A.-M.: conceptualization, methodology, data collection and analysis, drafting, reviewing, and editing of the manuscript, Q.L.: conceptualization, study design, data interpretation, editing, and reviewing, M.M.S.: data collection, writing, editing, and reviewing, P.S.: editing, reviewing, and funding, M.M.H.M.: visualization, editing, and reviewing. All authors have read and agreed to the published version of the manuscript.

Funding: This Research work was supported by the basic research fund (201562030) of the Ocean University of China (OUC), Qingdao, China.

Institutional Review Board Statement: Not applicable.

Informed Consent Statement: Not applicable.

Data Availability Statement: Based on the reasonable ground, the data is available on request from the corresponding author.

Acknowledgments: The first author would like to express sincere gratitude to the Chinese Scholarship Council (CSC) and the SOA (State Oceanic Administration) for their financial support during his doctorate studies and this research work. The authors are grateful to the College of Fisheries, Ocean University, China, and Marine Fisheries Survey Management Unit along with the Marine Fisheries Office, Department of Fisheries, Bangladesh, for their cordial support for successful completion of this research. The authors are also grateful to Sayedur Rahman Chowdhury for his technical support in the map designing.

Conflicts of Interest: The authors declare no conflict of interest.

\section{References}

1. Hilborn, R.; Walters, C.J. Quantitative fisheries stock assessment: Choice, dynamics and uncertainty. Rev. Fish Biol. Fish. 1992, 2,177-178.

2. Froese, R.; Demirel, N.; Coro, G.; Kleisner, K.M.; Winker, H. Estimating fisheries reference points from catch and resilience. Fish Fish. 2017, 18, 506-526. [CrossRef]

3. Khatun, M.H.; Lupa, S.T.; Rahman, M.F.; Barman, P.P.; Liu, Q. Evaluation of Labeo calbasu fishery status using surplus production models in Kaptai reservoir, Bangladesh. Appl. Ecol. Environ. Res. 2019, 17, 2519-2532. [CrossRef]

4. Ji, Y.; Liu, Q.; Liao, B.; Zhang, Q.; Han, Y.N. Estimating biological reference points for large head hairtail (Trichiurus lepturus) fishery in the Yellow Sea and Bohai Sea. Acta Oceanol. Sin. 2019, 38, 20-26. [CrossRef]

5. Barman, P.P.; Karim, E.; Khatun, M.H.; Rahman, M.F.; Alam, M.S.; Liu, Q. Application of CMSY to estimate biological reference points of Bombay duck (Harpadon neherus) from the Bay of Bengal, Bangladesh. Appl. Ecol. Environ. Res. 2020, 18, 8023-8034. [CrossRef]

6. Froese, R. Keep it simple: Three indicators to deal with overfishing. Fish Fish. 2004, 5, 86-91. [CrossRef]

7. Hussain, M.G.; Hoq, M.E. (Eds.) Sustainable Management of Fisheries Resources of the Bay of Bengal. Support to Sustainable Management of the BOBLME Project; Bangladesh Fisheries Research Institute: Mymensingh, Bangladesh, 2010; Available online: https://www. researchgate.net/profile/M_G_Hussain/publication/283509739_Sustainable_Management_of_Fisheries_Resources_of_the_ Bay_of_Bengal/links/563c7f9a08ae405111a9d6ca/Sustainable-Management-of-Fisheries-Resources-of-the-Bay-of-Bengal.pdf (accessed on 22 June 2021).

8. Martell, S.; Froese, R. A simple method for estimating MSY from catch and resilience. Fish Fish. 2013, 14, 504-514. [CrossRef]

9. Islam, S. Perspectives of the coastal and marine fisheries of the Bay of Bengal, Bangladesh. Ocean Coast. Manag. 2003, 46, 763-796. [CrossRef]

10. Hossain, S. Biological aspects of the coastal and marine environment of Bangladesh. Ocean Coast. Manag. 2001, 44, 261-282. [CrossRef]

11. Murshed-e-Jahan, K.; Belton, B.; Viswanathan, K.K. Communication strategies for managing coastal fisheries conflicts in Bangladesh. Ocean Coast. Manag. 2014, 92, 65-73. [CrossRef]

12. Motomura, H.; Iwatsuki, Y. A new genus, Leptomelanosoma, for the polynemid fish previously known as Polydactylus indicus (Shaw, 1804) and a redescription of the species. Ichthyol. Res. 2001, 48, 13-21. [CrossRef]

13. DoF (Department of Fisheries). Yearbook of Fisheries Statistics of Bangladesh, 2019-2020; Department of Fisheries, Ministry of Fisheries and Livestock, Government of Bangladesh: Dhaka, Bangladesh, 2020; Volume 37.

14. Smith, J.L.B. The Sea Fishes of Southern Africa; Central News Agency Ltd.: Cape Town, South Africa, 1949.

15. Menon, A.G.K.; Babu Rao, M. Polynemidae. In FAO Species Identification Sheets for Fishery Purposes-Western Indian Ocean (Fishing Area 51); Fischer, W., Bianchi, G., Eds.; FAO: Rome, Italy, 1984; Volume 3, pp. 1-2.

16. Menon, A.G.K. Polynemidae. In FAO Species Identification Sheets for Fishery Purposes-Eastern Indian Ocean and Western Central Pacific (Fishing Area 57 and 71); Fischer, W., Whitehead, P.J.P., Eds.; FAO: Rome, Italy, 1974; Volume 3, pp. 1-2.

17. Shamsuzzaman, M.M.; Islam, M.M.; Tania, N.J.; Abdullah Al-Mamun, M.; Barman, P.P.; Xu, X. Fisheries resources of Bangladesh: Present status and future direction. Aquac. Fish. 2017, 2, 145-156. [CrossRef] 
18. Fanning, P.; Chowdhury, S.R.; Uddin, M.S.; Al-Mamun, M.A. Marine Fisheries Survey Reports and Stock Assessment 2019; Bangladesh Marine Fisheries Capacity Building Project, Department of Fisheries, Ministry of Fisheries and Livestock: Dhaka, Bangladesh, 2019. Available online: http://mfsmu.fisheries.gov.bd/site/download/03cb42dc-8a4f-4dd3-a08943e5f5bcf61b (accessed on 22 June 2021).

19. Hussain, M.G.; Rahman, M.J. Marine Fisheries Resources of Bangladesh: Stock Status and Management Issues. Sustainable Management of Fisheries Resources of the Bay of Bengal; Support to BOBLME Project; Bangladesh Fisheries Research Institute: Mymensingh, Bangladesh, 2010; pp. 37-51. Available online: http://www.boblmebangladesh.org/SBOBLME\%20Publications/1.Sustainable\% 20management $\% 20$ of $\% 20$ fisheries $\% 20$ resources $\% 20$ of $\% 20$ the $\% 20$ BoB.pdf\#page $=44$ (accessed on 5 January 2022).

20. Schaefer, M.B. Some aspects of the dynamics of populations important to the management of the commercial marine fisheries. Int.-Am. Trop. Tuna Comm. Bull. 1954, 1, 23-56. [CrossRef]

21. Pauly, D.; Morgan, G.R. Length-Based Methods in Fisheries Research; World Fish: Penang, Malaysia, 1987.

22. Liang, C.; Pauly, D. Growth and mortality of exploited fishes in China's coastal seas and their uses for yield-per-recruit analyses. J. Appl. Ichthyol. 2017, 33, 746-756. [CrossRef]

23. Liang, C.; Xian, W.; Liu, S.; Pauly, D. Assessments of 14 exploited fish and invertebrate stocks in Chinese waters using the LBB method. Front. Mar. Sci. 2020, 7, 314. [CrossRef]

24. Froese, R.; Winker, H.; Coro, G.; Demirel, N.; Tsikliras, A.C.; Dimarchopoulou, D.; Scarcella, G.; Probst, W.N.; Dureuil, M.; Pauly, D. A Simple User Guide for LBB (LBB_33a.R). 2019. Available online: http:/ / oceanrep.geomar.de/44832/ (accessed on 23 June 2021).

25. Froese, R.; Demirel, N.; Gianpaolo, C.; Winker, H.; A Simple User Guide for CMSY+ and BSM (CMSY_2019_9f.R). December 2019. Available online: https:/ / oceanrep.geomar.de/33076/ (accessed on 23 June 2021).

26. Plummer, M. JAGS: A program for analysis of Bayesian graphical models using Gibbs sampling. In Proceedings of the 3rd International Workshop on Distributed Statistical Computing, Vienna, Austria, 20-22 March 2003; Volume 124, pp. 1-10.

27. Froese, R.; Winker, H.; Coro, G.; Demirel, N.; Tsikliras, A.C.; Dimarchopoulou, D.; Scarcella, G.; Probst, W.N.; Dureuil, M.; Pauly, D. A new approach for estimating stock status from length frequency data. ICES J. Mar. Sci. 2018, 75, 2004-2015. [CrossRef]

28. Palomares, M.L.D.; Froese, R. Training on the use of CMSY for the assessment of fish stocks in data-poor environments. In Workshop Report Submitted to the GIZ by Quantitative Aquatics, Inc. Q-Quatics; Technical Report No. 2; Quantitative Aquatics, Inc.: Laguna, Philippines, 2017; pp. 4-16.

29. Froese, R.; Pauly, D. Fishbase. Available online: https:/ / fishbase.mnhn.fr/search.php (accessed on 5 January 2022).

30. Ricker, W.E. Computation and interpretation of biological statistics of fish populations. Bull. Fish. Res. Board Can. 1975, 191, 1-382. [CrossRef]

31. Haddon, M. Modelling and Quantitative Methods in Fisheries, 2nd ed.; Chapman and Hall/CRC: Boca Raton, FL, USA, 2011. [CrossRef]

32. Carruthers, T.R.; Punt, A.; Walters, C.J.; MacCall, A.; McAllister, M.K.; Dick, E.J.; Cope, J. Evaluating methods for setting catch limits in data-limited fisheries. Fish. Res. 2014, 153, 48-68. [CrossRef]

33. Froese, R.; Pauly, D. Fishbase. Version (02/2015) Worldwide Web Electronic Publication. Available online: http:/ /www.fishbase. org (accessed on 15 November 2021).

34. MacCall, A.D. Depletion-corrected average catch: A simple formula for estimating sustainable yields in data-poor situations. ICES J. Mar. Sci. 2009, 66, 2267-2271. [CrossRef]

35. Dick, E.; MacCall, A.D. Depletion-based stock reduction analysis: A catch-based method for determining sustainable yields for data-poor fish stocks. Fish. Res. 2011, 110, 331-341. [CrossRef]

36. Palomares, M.L.D.; Froese, R.; Derrick, B.; Nöel, S.-L.; Tsui, G.; Woroniak, J.; Pauly, D. A preliminary global assessment of the status of exploited marine fish and invertebrate populations. In A Report Prepared by the Sea around Us for OCEANA; The University of British Columbia: Vancouver, BC, Canada, 2018.

37. Ghosh, S.; Muktha, M.; Rao, M.H.; Behera, P.R. Assessment of stock status of the exploited fishery resources in northern Bay of Bengal using landed catch data. Indian J. Fish. 2015, 62, 23-30. Available online: https://www.researchgate.net/profile/ Pralaya-Behera/publication/289196671_Assessment_of_stock_status_of_the_exploited_fishery_resources_in_northern_Bay_ of_Bengal_using_landed_catch_data/links/568a326b08ae1975839d67fd/Assessment-of-stock-status-of-the-exploited-fisheryresources-in-northern-Bay-of-Bengal-using-landed-catch-data.pdf (accessed on 9 January 2022).

38. Chuenpagdee, R.; Morgan, L.E.; Maxwell, S.M.; Norse, E.A.; Pauly, D. Shifting gears: Assessing collateral impacts of fishing methods in US waters. Front. Ecol. Environ. 2003, 1, 517-524. [CrossRef]

39. Gattuso, J.-P.; Magnan, A.K.; Bopp, L.; Cheung, W.W.L.; Duarte, C.M.; Hinkel, J.; McLeod, E.; Micheli, F.; Oschlies, A.; Williamson, P.; et al. Ocean solutions to address climate change and its effects on marine ecosystems. Front. Mar. Sci. 2018, 5, 337. [CrossRef] 